\title{
BMJ Open Non-operative treatment for lumbar spinal stenosis with neurogenic claudication: an updated systematic review
}

\author{
Carlo Ammendolia (D) ,1,2 Corey Hofkirchner, ${ }^{3}$ Joshua Plener, ${ }^{3}$ \\ André Bussières (1) , ${ }^{4,5}$ Michael J Schneider, ${ }^{6}$ James J Young (1) , 3,7 \\ Andrea D Furlan (10) ${ }^{8,9}$ Kent Stuber, ${ }^{3}$ Aksa Ahmed, ${ }^{2}$ Carol Cancelliere, ${ }^{10}$ \\ Aleisha Adeboyejo, ${ }^{3}$ Joseph Ornelas ${ }^{11}$
}

To cite: Ammendolia C, Hofkirchner C, Plener J, et al. Non-operative treatment for lumbar spinal stenosis with neurogenic claudication: an updated systematic review. BMJ Open 2022;12:e057724. doi:10.1136/ bmjopen-2021-057724

- Prepublication history and additional supplemental material for this paper are available online. To view these files, please visit the journal online (http://dx.doi.org/10.1136/ bmjopen-2021-057724).

Received 27 September 2021 Accepted 15 December 2021

Check for updates

(C) Author(s) (or their employer(s)) 2022. Re-use permitted under CC BY-NC. No commercial re-use. See rights and permissions. Published by BMJ.

For numbered affiliations see end of article.

Correspondence to Dr Carlo Ammendolia; cammendolia@mtsinai.on.ca

\section{ABSTRACT}

Objectives Neurogenic claudication due to lumbar spinal stenosis (LSS) is a growing health problem in older adults. We updated our previous Cochrane review (2013) to determine the effectiveness of non-operative treatment of LSS with neurogenic claudication.

Design A systematic review.

Data sources CENTRAL, MEDLINE, EMBASE, CINAHL and Index to Chiropractic Literature databases were searched and updated up to 22 July 2020.

Eligibility criteria We only included randomised controlled trials published in English where at least one arm provided data on non-operative treatment and included participants diagnosed with neurogenic claudication with imaging confirmed LSS.

Data extraction and synthesis Two independent reviewers extracted data and assessed risk of bias using the Cochrane Risk of Bias Tool 1. Grading of Recommendations Assessment, Development and Evaluation was used for evidence synthesis.

Results 0 15200 citations screened, 156 were assessed and 23 new trials were identified. There is moderatequality evidence from three trials that: Manual therapy and exercise provides superior and clinically important shortterm improvement in symptoms and function compared with medical care or community-based group exercise; manual therapy, education and exercise delivered using a cognitive-behavioural approach demonstrates superior and clinically important improvements in walking distance in the immediate to long term compared with self-directed home exercises and glucocorticoid plus lidocaine injection is more effective than lidocaine alone in improving statistical, but not clinically important improvements in pain and function in the short term. The remaining 20 new trials demonstrated lowquality or very low-quality evidence for all comparisons and outcomes, like the findings of our original review.

Conclusions There is moderate-quality evidence that a multimodal approach which includes manual therapy and exercise, with or without education, is an effective treatment and that epidural steroids are not effective for the management of LSS with neurogenic claudication. All other non-operative interventions provided insufficient quality evidence to make conclusions on their effectiveness.

\section{Strengths and limitations of this study}

- This systematic review included a wide range of non-operative interventions commonly used in clinical practice.

- This review used consistent inclusion and exclusion criteria for neurogenic claudication, which included the corroboration of a diagnosis of lumbar spinal stenosis with imaging.

- This review used rigorous methods recommended by the Cochrane Back and Neck Pain Review Group including the use of Grading of Recommendations, Assessment, Development and Evaluation to synthesise and summarise the quality of the evidence.

- Only English studies were included in this review.

- Most studies had small samples sizes with heterogeneity in interventions tested, limiting ability to pool data.

PROSPERO registration number CRD42020191860.

\section{INTRODUCTION}

Lumbar spinal stenosis (LSS) causing neurogenic claudication is a highly prevalent and rapidly growing public health problem among older adults. ${ }^{1}$ It is characterised by bilateral or unilateral buttock pain and/or lower extremity discomfort, pain, weakness or heaviness precipitated by walking and prolonged standing and relieved by stooping forward and sitting. ${ }^{2} 3$ The underlying aetiology is usually age-related osteoarthritic changes to lumbar intervertebral discs, facets joints and ligaments leading to narrowing of the central and/or lateral spinal canals and compression and/or ischaemia of the spinal nerves. ${ }^{24}$

Limited walking ability is the dominant impairment in neurogenic claudication and the most common reason for seeking care. ${ }^{5}$ Limited walking ability due to LSS is associated 
with a significant decline in functional status, quality of life and independence in this population. ${ }^{25}$

Although LSS is the most common reason for spine surgery in older adults, most people with neurogenic claudication receive non-operative care $^{6}$ A course of non-operative care is also recommended prior to receiving surgical intervention. ${ }^{7}$ However, what constitutes effective non-operative care remains unknown. In 2013, we published a Cochrane review evaluating nonoperative treatment for LSS causing neurogenic claudication. ${ }^{89}$ This review identified 21 randomised controlled trials (RCTs) assessing a variety of non-operative treatments. However, the quality of the evidence was deemed low or very low and therefore no conclusions could be made on the effectiveness of non-operative treatment for neurogenic claudication. The purpose of this study is to update this systematic review and the evidence for nonoperative treatments for neurogenic claudication. Our specific research question was: What non-operative interventions are effective in improving outcomes in patients with neurogenic claudication due to LSS?

\section{METHODS}

This systematic review was conducted and reported according to the Preferred Reporting Items for Systematic Reviews and Meta-Analyses guidelines. ${ }^{10}$ We used methods recommended by the Cochrane Back Review Group. ${ }^{11}$

\section{Patient and public involvement statement}

Patients or the public were not involved in the conduct of this systematic review.

\section{Population, interventions, comparison and outcomes criteria}

The population of interest was individuals with imaging confirmed LSS (central or foraminal, with or without spondylolisthesis) and neurogenic claudication. Neurogenic claudication is a clinical diagnosis and was defined as buttock or leg pain and/or aching, numbness, tingling, weakness or fatigue with or without back pain, precipitated by standing or walking. There were no age restrictions. The interventions of interest included all non-operative treatments and the comparison was any treatment including surgery. Outcomes included at least one of the following measures: walking ability, pain intensity, physical function, quality of life or global improvement.

\section{Search and study selection}

We replicated and updated our original electronic database search (from 1966 to January 2011) up to 22 July 2020. The search was performed by an experienced librarian in CENTRAL (Cochrane Library 2011 issue1), MEDLINE, EMBASE, CINAHL and Index to Chiropractic Literature databases. The terms 'spinal stenosis', 'lumbar spinal stenosis', 'neurogenic claudication', 'lumbar radicular pain', 'cauda equina' and 'spondylosis' were combined with a highly sensitive search strategy to identify RCTs.
Reference lists of selected studies and previous reviews were also searched to identify additional articles. Online supplemental file 1 provides details on the full search strategies used for all databases.

Studies were included if they were RCTs published in peer-reviewed English journals, at least one arm of the trial provided data on effectiveness of a non-operative treatment and at least $80 \%$ of subjects had neurogenic claudication with imaging confirmed LSS. Studies evaluating subjects with radiculopathy caused by disc herniations without neurogenic claudication were excluded.

Studies with mixed populations were only included if separate data for subjects with neurogenic claudication due to LSS were provided.

Two pairs of reviewers independently screened all titles and abstracts identified by the search strategy. Full text of articles deemed to be potentially relevant were independently assessed by two reviewers who made the final decision for inclusion. A third reviewer was consulted if consensus was not reached.

\section{Risk of bias assessment and data analysis}

Two reviewers independently assessed methodological risk of bias and performed data extraction. Safety data (intervention side effects and/or complications) when available were also collected. The Cochrane Risk of Bias Tool 1 was used that included the 12-item criteria recommended by the Cochrane Back Review Group. ${ }^{11}$ Discrepancies in risk of bias scoring and data extraction were resolved with discussion and if necessary, with a third reviewer until consensus was reached. Reviewers who were authors of any of the included studies were recused from performing risk of bias assessment, data extraction, data analysis or synthesis of their own studies.

Low risk of bias was defined as fulfilling 6 or more of the 12 criteria including clearly described and appropriate randomisation (item A), and allocation concealment (item B), and with no severe flaws. A severe flaw was defined a priori as a serious methodological deficiency not captured by the 12-item criteria that significantly increases the risk of bias such as very high dropout or cross-over rates and sample sizes less than 30 subjects per treatment arm.

For each comparison, outcomes were analysed according to these follow-up time periods: immediate (up to 1 week following the intervention); short term (between 1 week and 3 months); intermediate (between 3 months and 1 year) and long term (1 year or longer). Outcome data were pooled, and meta-analyses were performed when trials were judged to be sufficiently homogeneous, both clinically and statistically.

Rehabilitation therapy was defined as treatment that used any combination of education, exercise instruction, manual therapy, heat and cold applications, electrotherapy, other physical therapy modalities, orthosis and other assistive devices. Multimodal treatment included various combinations of rehabilitation therapy 
treatments, oral and other mediations and spinal injections, but not surgery.

\section{Data synthesis}

The quality of the evidence for each outcome and for each comparison was evaluated using Grading of Recommendations, Assessment, Development and Evaluation (GRADE). ${ }^{12} 13$ Overall quality of the evidence was based on performance against five domains: (1) risk of bias; (2) consistency of findings; (3) directness of comparisons; (4) precision of estimates and (5) other considerations such as selective reporting.

The quality of the evidence starts at high when there are consistent findings among at least $75 \%$ of RCTs with low risk of bias and consistent, direct and precise data and with no known or suspected publication bias. It downgrades a level for each domain not met. Treatment effects between comparators (more effective, less effective or no difference) were based on statistically significant and clinically important differences in outcomes.

\section{High-quality evidence}

All five domains are met; further research is very unlikely to change the confidence in the estimate of effect.

\section{Moderate-quality evidence}

One of the domains is not met; further research is likely to have an important impact on the confidence in the estimate of effect and may change the estimate.

\section{Low-quality evidence}

Two domains are not met; further research is very likely to have an important impact in the confidence of the estimate of effect and is likely to change the estimate.

\section{Very low-quality evidence}

Three or more domains are not met; there is great uncertainty about the estimate of effect.

Evidence provided by a single small trial was considered inconsistent and imprecise and thus provide 'low' or 'very low' quality evidence, depending on whether it was assessed as having a low or high risk of bias, respectively, and there were no other limitations. Studies with both low risk of bias and inappropriate or unclear randomisation and/or treatment allocation techniques were downgraded by two levels for the 'risk of bias' domain.

The results below are reported based on statistically significant differences between comparators for each outcome using data reported by authors. Differences considered clinically important will be specified when the quality of the evidence is moderate or higher. The minimal clinical important differences (MCIDs) used are listed in the online supplemental table 2. Adverse events for the new studies are detailed when reported by the authors.

\section{RESULTS}

\section{Selection and description of included trials}

We screened 15200 titles and abstracts and assessed 156 full-text articles. This resulted in 44 RCTs meeting the inclusion criteria, including 23 new trials. Figure 1 summarises original and updated screening results. Online supplemental table 1 describes the characteristics of all included trials. In total, 3792 participants (1765 males, 1836 females and 191 participants of undisclosed gender ${ }^{14} 15$ were randomised to one of the 60 comparison groups. In total, 17 studies evaluated rehabilitation therapy or multimodal care, ${ }^{14} 16-3111$ assessed epidural injections, ${ }^{32-42} 7$ evaluated oral medications, ${ }^{15} 43-48 \quad 6$ assessed calcitonin, ${ }^{49-54} 2$ evaluated acupuncture ${ }^{55} 56$ and 1 assessed spinal manipulation. ${ }^{57}$ Thirty-eight trials were conducted at tertiary care or university affiliated centres and six at medical/rehabilitation clinics. ${ }^{18} 24$ 35-38 The mean age of participants was 63.3 years. The duration of symptoms varied considerably among the studies with a mean ranging from 12 weeks to 15 years. Follow-up periods also varied significantly ranging from immediately following the intervention to 10 years post intervention.

\section{Risk of bias of included studies}

The median and mean number of criteria met was 7 of 12 (range 2-11), see table 1.

Although 31 studies met six or more criteria, only 9 were considered to have low risk of bias. 19202427283137424356 Among the remaining 22 studies that met six or more criteria, 13 failed to explicitly describe and/or use appropriate randomisation procedures, allocation concealment

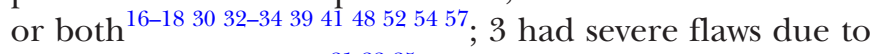
high cross-over rates, ${ }^{21} 2225$ which made the intention-totreat analyses uninterpretable and 6 had other serious flaws including premature stopping of the trial, ${ }^{47}$ large number of participants lost to follow-up ${ }^{40}$ and small sample size (less than 30 participants per arm). ${ }^{26} 294655$

\section{Evidence of effect of interventions}

Overall, 53 of the 60 comparisons were examined in a single trial, most with small sample sizes. It was only possible to combine data from two trials (assessing surgery vs multimodal treatment) for one outcome in a meta-analysis. ${ }^{19}{ }^{22}$ The five other studies (all assessing calcitonin $)^{49-5254}$ were combined qualitatively. The results of these pooled analyses were published in our previous reviews. ${ }^{89}$ Heterogeneity in source population, intervention and outcome instruments precluded pooling of data from other trials. Online supplemental table 2, summary of GRADE assessment and outcomes, summarises the quality of the evidence for outcomes for each comparison.

\section{Calcitonin}

There were no new studies assessing calcitonin. The conclusion from our previous review was that there is very low-quality evidence from six trials $(\mathrm{N}=231)^{49-54}$ 


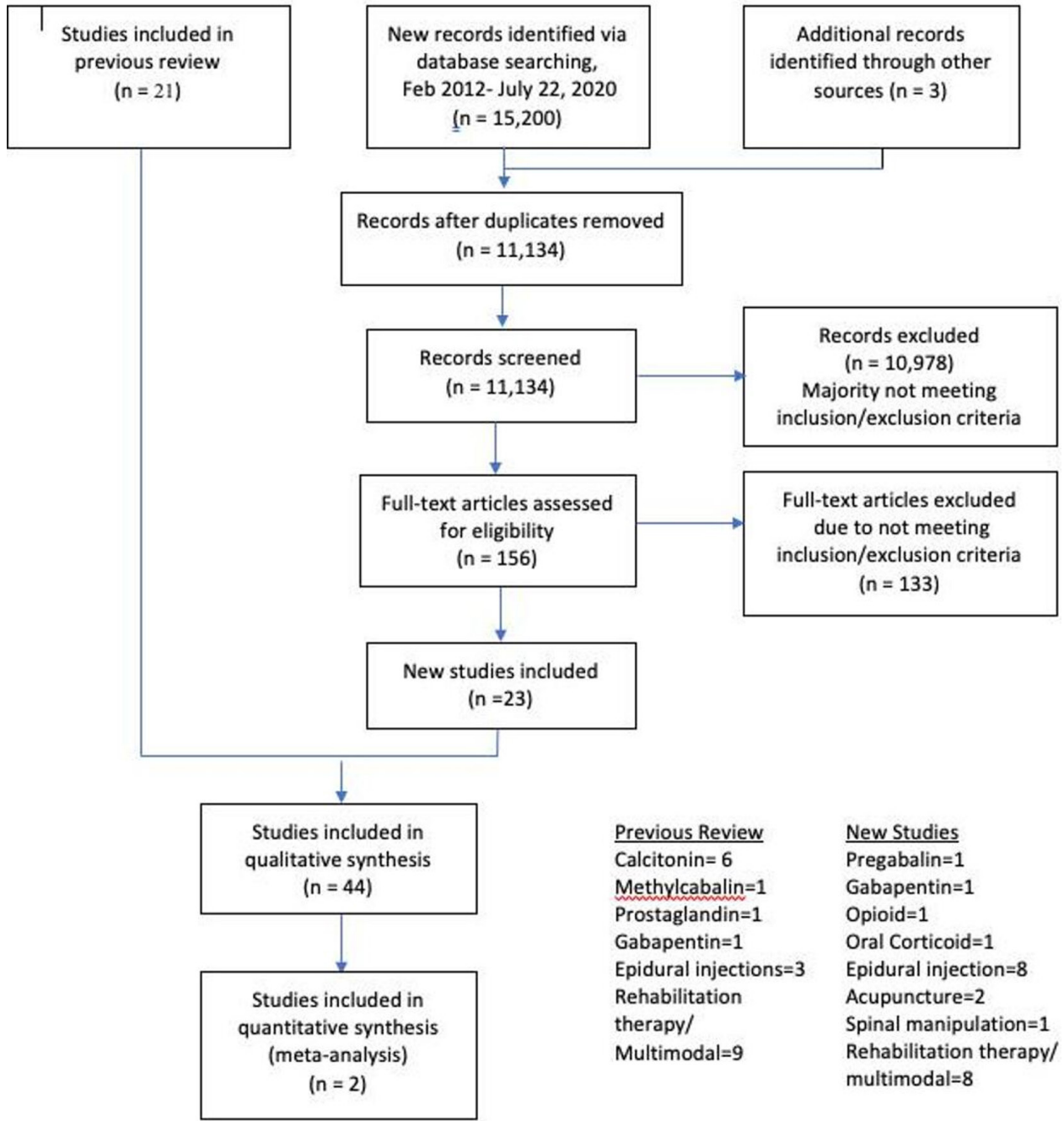

Figure 1 Study flow diagram.

that calcitonin is no better than placebo or paracetamol regardless of mode of administration or outcome assessed.

\section{Oral medication}

We identified four new studies assessing five oral medications. There is low-quality evidence based on one small cross-over trial $(\mathrm{N}=29)^{46}$ that pregabalin does not improve pain, distance walked, function or global health status immediately following the intervention compared with placebo. Adverse events were reported in $64 \%$ of the pregabalin group, the most common being dizziness, compared with $35 \%$ in the placebo group.

A small trial evaluating gabapentin plus conservative care $(\mathrm{N}=45)^{48}$ provides very low-quality evidence demonstrating no significant improvement in back/ leg pain, disability scores or global health in the short term compared with conservative care plus botulinum toxin injection. Five patients $(20.8 \%)$ reported mild-tomoderate pain at injection sites for a few days after botulinum toxin injections.

There is very low-quality evidence from one small trial $(\mathrm{N}=24)^{47}$ that oxymorphone hydrochloride or propoxyphene and acetaminophen are no better than placebo in the immediate term for all outcomes assessed.

A single small trial provided very low-quality evidence $(\mathrm{N}=61)^{15}$ that oral corticoids do not improve outcomes in the short term compared with placebo.

The original review identified three studies assessing oral medications and concluded that there is low-quality evidence that prostaglandins improve walking distance and leg pain in the short term compared with etodolac (a non-steroidal anti-inflammatory drug) $;^{43}$ that there is very low-quality evidence that gabapentin improves walking distance and pain compared with placebo in the intermediate and long term ${ }^{45}$ and that methylcobalamin (vitamin B 12) plus conservative treatment improves walking distance in the intermediate and long term compared with conservative treatment alone. ${ }^{44}$

\section{Rehabilitation therapy and multimodal treatment}

We identified eight new studies evaluating 13 rehabilitation therapy and/or multimodal treatment approaches, with one study being compared with surgery. 
焉

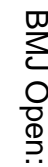

$\stackrel{\overrightarrow{\vec{D}}}{\stackrel{9}{+}}$

흠

$\frac{\bar{c}}{\frac{5}{5}}$
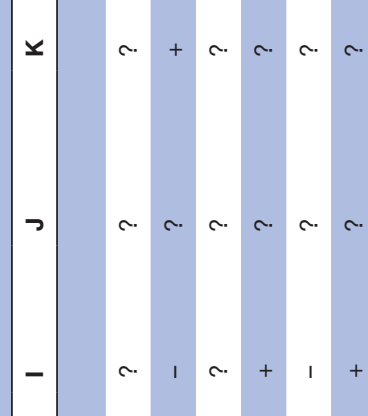


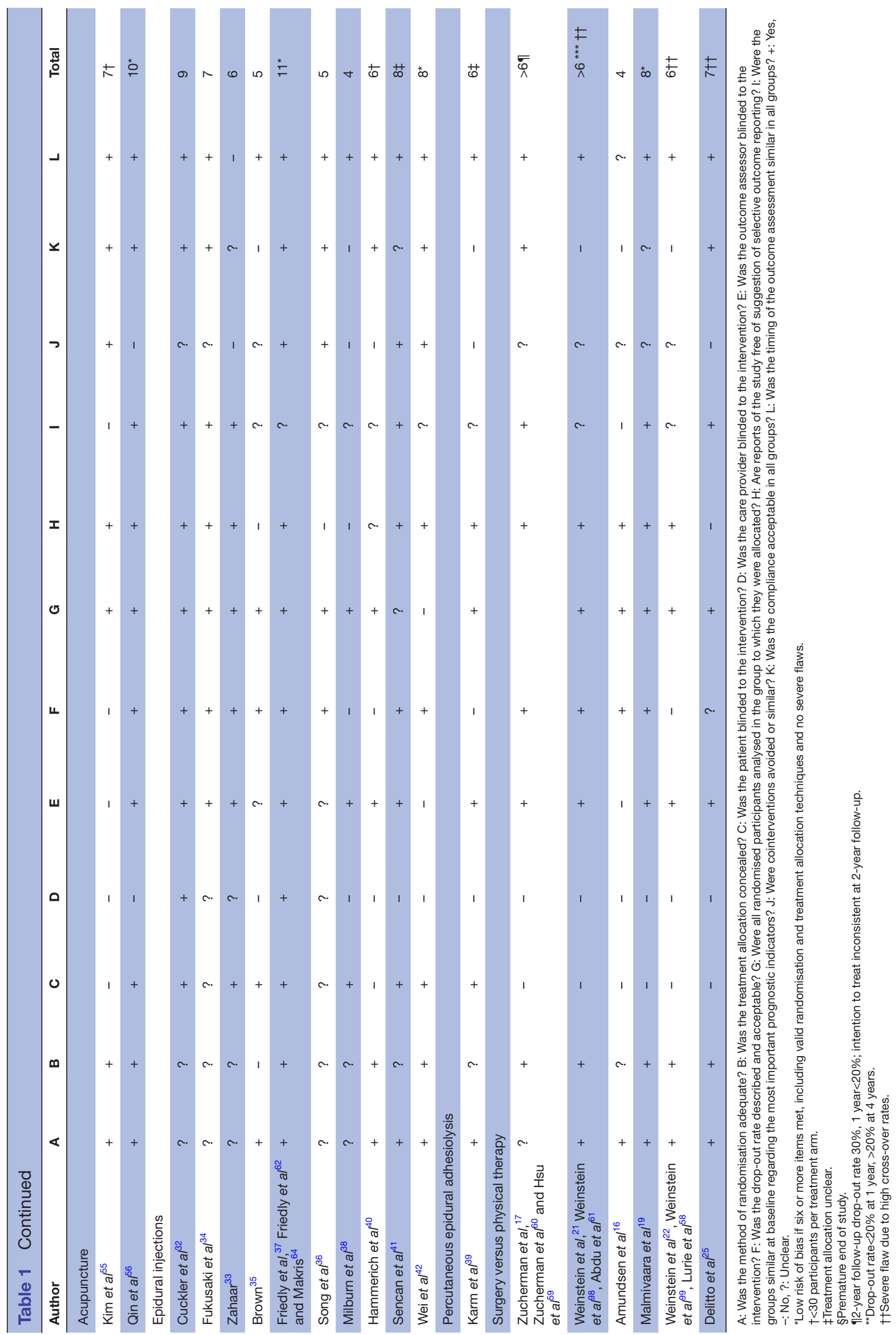


There is moderate-quality evidence from one trial $(\mathrm{N}=259)^{31}$ that manual therapy and exercise provides superior and clinically important short-term improvement in symptoms and function compared with medical care or community-based group exercise and that community-based group exercise improves physical activity in the short term compared with medical care. There were no reported serious adverse events in any group. There was a significantly greater rate of transient joint soreness associated with the manual therapy and exercise group (49\%) compared with the community-based group exercise $(31 \%)$ and medical care $(6 \%)$ groups.

Another trial provides moderate-quality evidence $(\mathrm{N}=104)^{27}$ that comprehensive care (manual therapy, education and exercise delivered using a cognitivebehavioural approach) demonstrates superior and clinically important improvements in walking distance in the immediate, short, intermediate and long term and compared with self-directed home exercise. This study also provides low-quality evidence that comprehensive care improves overall pain and function in the long term compared with self-directed home exercises. At 12 months, none of the 43 participants in the comprehensive group and 2 of the 46 participants in the self-directed group experienced adverse events. These adverse events were mostly attributed to a temporary increase in low back and/or leg pain.

There is low-quality evidence from one trial $(\mathrm{N}=34)^{28}$ that a form of manual therapy (Mokuri Chuna), acupuncture and physician care, with or without a herbal remedy (Gang-Chuk Tang), improves low back pain in the intermediate term compared with oral aceclofenac, epidural steroids and physical therapy (heat and TENS).

A single study assessing supervised physical therapy (manual therapy, exercise and body weight-supported treadmill) $(\mathrm{N}=86)^{30}$ provides low-quality evidence for improved symptoms, function and walking distance in the short term compared with home exercises.

There is very low-quality evidence from one study $(\mathrm{N}=120)^{14}$ that heat, transcutaneous electrical nerve stimulation (TENS) and home exercise instruction are no better than isokinetic exercise in the immediate, short and intermediate term for all outcomes and less effective than unloaded exercises in the immediate and short term. Unloaded exercise was also found to be superior to isokinetic exercise in the immediate and short term.

One small single study $(\mathrm{N}=47)^{26}$ provides very lowquality evidence that aquatic exercise is more effective than physical therapy (exercise, ultrasound, heat and TENS) in improving pain and walking distance in the immediate term.

Another small single trial $(\mathrm{N}=40)^{29}$ provides very lowquality evidence that a presurgical exercise programme improves postsurgical outcomes in the immediate, but not in the short or intermediate terms.

There is low-quality evidence from one study $(\mathrm{N}=169)^{25}$ that a structured physical therapy programme (education and exercises) provides similar outcomes to decompression surgery in the long term (2-year follow-up). Overall, 9 out of 82 participants receiving physical therapy reported adverse events consisting of worsening of symptoms, whereas 33 out 87 participants reported surgery-related complications, mainly attributable to reoperation, delay in wound healing and surgical site infection.

Our original review identified nine rehabilitation therapy/multimodal trials of which five were compared with surgical interventions. A meta-analysis was conducted for two of the surgical trials. Two of the original surgical trials have since published 8-year follow-up results (see below). All studies provide either low-quality or very lowquality evidence.

A meta-analysis ${ }^{8}{ }^{9}$ that includes two trials ${ }^{22}{ }^{19}$ shows that laminectomy improves outcomes only at the 2-year follow-up compared with conservative care. One of these studies shows no difference in outcomes after an 8-year follow-up. ${ }^{58}$

An interspinous surgical implant ${ }^{175960}$ was found to be superior to multimodal treatment (epidural injections, pain medication, education, exercise, back brace, heat/ ice and massage). Another trial ${ }^{16}$ provided inconclusive evidence when comparing laminectomy with or without fusion to lumbar orthosis and education.

Among patients with degenerative spondylolisthesis, one study ${ }^{21}$ shows no difference in outcomes with laminectomy when compared with conservative care, including after an 8-year follow-up. ${ }^{61}$

One study showed that exercise plus ultrasound is no better than exercise plus sham ultrasound but better than no treatment, and exercise plus sham ultrasound is better than no treatment. ${ }^{24}$ Other studies demonstrated that inpatient physical therapy (ultrasound, heat and TENS) is more effective than home exercise plus oral diclofenac, ${ }^{23}$ unweighted treadmill walking plus exercise is no better than cycling plus exercise ${ }^{20}$ and manual therapy, exercise and unweighted treadmill are more effective than flexion exercises, walking and sham ultrasound. ${ }^{18}$

\section{Epidural injections}

We identified six new studies evaluating epidural injections. There is moderate-quality evidence from one study $(\mathrm{N}=400)^{37} 62$ that glucocorticoid plus lidocaine injection is better than lidocaine alone in improving pain and function at 3 weeks (short term) but not at 6 weeks (short term), 12 weeks (intermediate term) or 12 months (long term). The improved outcomes at 3 weeks were statistically significant but not considered to be of clinical importance. ${ }^{63} \mathrm{~A}$ follow-up subgroup analysis $^{64}$ using patient-prioritised Roland-Morris Disability Questionnaire items did not change the results. A total $21.5 \%$ of patients in the glucocorticoid-lidocaine group and $15.5 \%$ in the lidocaine alone group reported one or more adverse events $(p=0.08)$. Adverse events included headaches, fever, infection, dizziness, cardiovascular/ lung problems, leg swelling and dural puncture. 
A small study $(\mathrm{N}=29)^{36}$ provided very low-quality evidence that an injection of lidocaine is no better than a saline injection for all outcomes in the short term.

There is very low-quality evidence from one study $(\mathrm{N}=57)^{38}$ that steroid injections at the level of maximal stenosis improve pain and function in the immediate and short term compared with steroid injections at two levels cephalad to the maximum level of stenosis.

A small trial $(\mathrm{N}=54)^{40}$ provided very low-quality evidence that steroid injections are no better than steroid injections combined with physical therapy (manual therapy and exercise) in improving pain or function in the short term but are more effective in improving pain in the intermediate and long term.

There is very low-quality evidence from one study $(\mathrm{N}=67)^{41}$ that interlaminar steroid injection improves pain and walking distance in the intermediate but not in the short term compared with transforaminal steroid injection.

A three-arm trial $(\mathrm{N}=30)^{42}$ provided low-quality evidence that tumour necrosis factor (TNF) alpha inhibitor (etanercept) injections improved pain and function in the immediate, short and intermediate term compared with steroid or lidocaine injections and that steroid injections were no better than lidocaine for all outcomes and follow-up periods.

There is very low-quality evidence from one small trial $(\mathrm{N}=38)^{35}$ that minimally invasive lumbar decompression surgery is no better than epidural steroid injections for all outcomes in the short term.

One small trial $(\mathrm{N}=44)^{39}$ provided very low-quality evidence that an epidural inflatable balloon catheter (ZiNeu) improves pain and function in the intermediate term but not in the short term compared with a balloonless catheter (Racz). Minor and transient adverse events were reported equally in both groups (no data provided), mostly pain and paraesthesia at the injection site.

Our original review identified four trials evaluating seven epidural injection approaches, all with very lowquality evidence for all outcomes. Two trials demonstrated that translaminar ${ }^{32}$ or caudal ${ }^{33}$ steroid injections were no better than placebo. Two other trials showed that translaminar epidural steroid plus a block was better than placebo or an epidural block alone, ${ }^{34}$ that translaminar epidural block was better than placebo ${ }^{34}$ and that interlaminar epidural steroid plus a block was better than home exercise plus diclofenac or inpatient physical therapy (ultrasound, heat and TENS). ${ }^{23}$

\section{Acupuncture}

We identified two new studies assessing acupuncture. There is low-quality evidence from one trial $(\mathrm{N}=80)^{56}$ that acupuncture improves back and leg pain, symptoms and function in the immediate, short and intermediate term compared with sham acupuncture. Overall, 3 out of 40 participants in the acupuncture group reported shortterm pain at the insertion site (one also had a haematoma) and 5 out of the 40 participants in the sham group reported non-serious back pain or fatigue. There is very low-quality evidence from a small trial $(\mathrm{N}=50)^{55}$ that acupuncture plus usual care is no better than usual care alone in the short term for all outcomes.

\section{Spinal manipulation}

We identified one study assessing spinal manipulation. There is very low-quality evidence from a very small trial $(\mathrm{N}=14)^{57}$ that spinal manipulation alone is no better than a wait list control in the immediate term for all outcomes.

\section{DISCUSSION}

We updated our systematic review on non-operative treatments for LSS causing neurogenic claudication and identified 23 new trials that were added to the previous 21 studies. The highest number of studies, 17/44, evaluated rehabilitation therapy/multimodal treatment, 11 assessed epidural interventions, 7 assessed oral medications, 6 assessed calcitonin, 2 evaluated acupuncture and 1 assessed spinal manipulation. Of the 60 comparisons that were evaluated, 5 comparisons from three trials $^{27} 3137$ provided moderate-quality evidence. The remaining comparisons provide either low-quality or very low-quality evidence. In our original review, all comparisons for all the interventions assessed were of low-quality or very low-quality evidence. This lack of moderate-quality or high-quality evidence limited our ability to make conclusions on the effectiveness of most non-operative treatments.

There is now moderate evidence that a multimodal structured 6-week programme consisting of manual therapy and exercise with or without education is an effective treatment approach ${ }^{27}{ }^{31}$ for neurogenic claudication and that epidural steroid injections do not provide clinically important improvements in short-term or long-term outcomes compared with epidural lidocaine injections. However, given that these respective findings came from single studies, this evidence lacks consistency and therefore there is a possibility that replicating these trials in the future might result in substantially different conclusions. However, a recent clinical practice guideline for the management of LSS leading to neurogenic claudication concurred with our findings and recommended, based on moderate-quality evidence, multimodal care consisting of education with home exercises and manual therapy. ${ }^{65}$ These guidelines also recommended against the use of epidural steroid injections, based on high-quality evidence. A recent systematic review and meta-analysis of RCTs evaluating conservative non-pharmacological therapies for degenerative LSS also concluded, based on low-tomoderate evidence, that manual therapy and supervised exercises significantly improve outcomes compared with self-directed or group exercises ${ }^{66}$ A recent clinical update published in the British Medical Journal recommended supervised exercise and manual therapy as a first-line treatment for LSS and recommended against the use of epidural steroid injections. ${ }^{67}$ More dated systematic 
reviews did not recommend a combination of education, exercise and manual therapy as an effective treatment for LSS. ${ }^{76869}$ However, these reviews did not include the more recent higher quality trials ${ }^{2731}$ evaluating this multimodal approach.

A multimodal approach to the treatment of LSS would appear to be a rational approach given the complexity of neurogenic claudication with underlying physical, functional and psychosocial factors impacting recovery. ${ }^{70}$ There is also a plausible rationale for the lack of effectiveness of epidural steroid injections for neurogenic claudication since the dominant underlying pathophysiological mechanism appears to be neuroischaemia rather than neuroinflammation. ${ }^{4}$

Although we cannot make firm conclusions about the effectiveness of non-operative treatments for neurogenic claudication, this review is important because it provides important information regarding the state of current evidence regarding non-operative treatments. This can be used to inform clinical practice guidelines and aid clinicians and patients in making clinical decisions regarding treatment options. This is particularly important with respect to interventions that have higher risks and costs such as epidural injections and surgery. About 25\% of all epidural injections are performed for LSS $^{71} 72$ yet the evidence from our current review and those of others ${ }^{73-75}$ do not support their use. The number and associated costs of surgical procedures for degenerative LSS are growing, especially decompression surgery with complex fusion. ${ }^{77}$ LSS continues to be the most common reason for spine surgery in older adults. ${ }^{6} 76$ High-quality evidence for the effectiveness of surgery is also lacking based on our current review and the findings of other systematic reviews. ${ }^{78}{ }^{79}$ Clinical trials evaluating surgery for LSS are difficult to conduct due to challenges in recruitment and blinding (patient and practitioner) and high costs. ${ }^{80}$ One ongoing clinical trial is comparing decompression surgery with sham surgery which should help to evaluate the potential role of the placebo effect of surgery for LSS. ${ }^{81}$

Oral medication is often the first-line treatment in primary care management of LSS. ${ }^{5}$ Pregabalin and gabapentin are commonly prescribed medications for LSS despite the growing evidence that these medications are not effective for back-related leg symptoms and may cause more harm than good. ${ }^{82-84}$

New to this updated review are clinical trials on acupuncture and spinal manipulation; however, the quality of the evidence was insufficient to make conclusions on their effectiveness. A systematic review and meta-analysis of RCTs and controlled clinical trials published in Chinese found no conclusive evidence for the effectiveness and safety of acupuncture for LSS. ${ }^{85}$ Passive unimodal treatments such as acupuncture and spinal manipulation are unlikely to provide long-term benefit but more likely to provide benefit when combined with a comprehensive approach to managing LSS, ${ }^{27}$ not unlike recommendations for managing chronic low back pain. ${ }^{86}$
This review is also important because it provides a comprehensive assessment and identification of significant knowledge gaps in this area to guide future research. This includes the need for higher quality studies that assess commonly used non-operative treatments particularly in primary care settings that are adequately powered and have low risk of bias and long-term follow-up. Future RCTs should follow the Consolidated Standards of Reporting Trials guideline ${ }^{87}$ when planning trials and reporting study findings in an attempt to improve transparency and reduce bias.

The strengths of this review include the evaluation of a wide range of non-operative interventions and the use of consistent inclusion and exclusion criteria for neurogenic claudication, which included the corroboration of a diagnosis of LSS with imaging. The use of these criteria to define the study population increases the likelihood that participants in the included studies had the diagnosis of neurogenic claudication due to narrowing of the central canal or lateral foraminae ${ }^{88-90}$ Other strengths of this review include the use of rigorous methods recommended by the Cochrane Collaboration, the WHO and the Cochrane Back and Neck Pain Review Group. ${ }^{13}$ This included the use of the GRADE method to synthesise and summarise the quality of the evidence.

Limitations of this review include the potential for language bias because only English articles were accepted. We also included studies with small samples sizes which are more prone to high risk of bias. ${ }^{91}$ Over half of the included studies had less than 30 subjects per arm at baseline and none of these studies could be pooled because of high heterogeneity across studies. However, the exclusion of studies with small samples sizes in this review would not have changed our conclusions. The definition of a severe flaw and the cut-off point of 6 or more to differentiate trials of low from high risk of bias were arbitrary, therefore alternative definitions and cut-off points or the use of other risk of bias tools could have impacted the findings and conclusions of this review. The validity of MCIDs used in this review is unknown. Although most were derived from studies with neurogenic claudication, ${ }^{639293}$ others were based on an arbitrary improvement of at least $30 \%{ }^{94}$ There are no agreed upon MCIDs in LSS and therefore different MCIDs thresholds could have potentially altered our conclusions. The location and severity of the stenosis on imaging was not deemed important in this review. Imaging findings often do not correlate with patient symptoms or severity and therefore imaging by itself is a not reliable diagnostic tool in this population. ${ }^{679596}$ Neurogenic claudication is the clinical entity of interest in this review and, although usually caused by LSS, the diagnosis is made clinically without imaging. ${ }^{97}$ Neurogenic claudication symptoms, by definitions, improve with flexion, due to the increased volume around the involved nerve roots irrespective of where the stenosis is located (eg, centrally or at the lateral recess). However, it is uncertain whether the effectiveness of some interventions, such as epidural steroid injections, is dependent on 
location of the spinal stenosis. This is a different research question requiring future research.

\section{CONCLUSIONS}

There is moderate-quality evidence that a multimodal approach that includes manual therapy and exercise, with or without education, is a safe and effective treatment and that epidural steroids are not effective for the management of LSS causing neurogenic claudication. All other studies evaluating non-operative interventions provided insufficient quality evidence, limiting the ability to make conclusions about their effectiveness. With the growing prevalence and significant personal, social and economic burden of LSS, more high-quality evidence for non-operative interventions is urgently needed to guide clinical practice.

\author{
Author affiliations \\ ${ }^{1}$ Faculty of Medicine, University of Toronto, Toronto, Ontario, Canada \\ ${ }^{2}$ Rheumatology, Sinai Health System, Toronto, Ontario, Canada \\ ${ }^{3}$ Graduate Education and Research, Canadian Memorial Chiropractic College, \\ Toronto, Ontario, Canada \\ ${ }^{4}$ School of Physical and Occupational Therapy, Faculy of Medicine and Health \\ Sciences, McGill University, Montreal, Quebec, Canada \\ ${ }^{5}$ Département Chiropratique, Université du Québec à Trois-Rivières, boulevard des \\ Forges, Trois-Rivières Québec, Canada \\ ${ }^{6}$ Physical Therapy, University of Pittsburgh, Pittsburgh, Pennsylvania, USA \\ ${ }^{7}$ Sports Medicine and Clinical Biomechanics, University of Southern Denmark, \\ Odense, Denmark \\ ${ }^{8}$ Toronto Rehabilitation Institute, Toronto, Ontario, Canada \\ ${ }^{9}$ Institute for Work \& Health, Toronto, Ontario, Canada \\ ${ }^{10}$ Faculty of Health Sciences, Ontario Tech University, Oshawa, Ontario, Canada \\ ${ }^{11}$ Health Systems Management, Rush University, Chicago, Illinois, USA
}

\section{Twitter Andrea D Furlan @adfurlan}

Acknowledgements The authors would like to thank librarian Maggie Tiong from the Institute for Work \& Health for her assistance in developing the search strategy and retrieving relevant articles and Carly Coelho for assistance in screening titles and abstracts.

Contributors CA acted as the study guarantor and was the involved in the conception and design of the study, screening of articles, risk of bias assessment, Grading of Recommendations, Assessment, Development and Evaluation (GRADE) analysis, writing the first draft of the manuscript, revision of the manuscript and administrative support. AB, MJS, ADF, CC and J0 were involved in screening of articles, risk of bias assessment, GRADE analysis and critical revision of the manuscript. CH, JP, AAhmed, KS, JY and AAdeboyejo participated in screening of articles, risk of bias assessment, data extraction and critical revision of the manuscript.

Funding The authors have not declared a specific grant for this research from any funding agency in the public, commercial or not-for-profit sectors.

Competing interests CA received research funding from the Canadian Chiropractic Research Foundation and the Arthritis Society. JY has received funding support from the Danish Foundation for Chiropractic Research and Postgraduate Education, the Ontario Chiropractic Association, the Canadian Memorial Chiropractic College, the National Chiropractic Mutual Insurance Company Foundation and the University of Southern Denmark. CC holds a Research Chair in Knowledge Translation in the Faculty of Health Sciences, Ontario Tech University, funded by the Canadian Chiropractic Research Foundation.

Patient consent for publication Not applicable.

Ethics approval This study does not involve human participants.

Provenance and peer review Not commissioned; externally peer reviewed.

Data availability statement All data relevant to the study are included in the article or uploaded as supplementary information.
Supplemental material This content has been supplied by the author(s). It has not been vetted by BMJ Publishing Group Limited (BMJ) and may not have been peer-reviewed. Any opinions or recommendations discussed are solely those of the author(s) and are not endorsed by BMJ. BMJ disclaims all liability and responsibility arising from any reliance placed on the content. Where the content includes any translated material, BMJ does not warrant the accuracy and reliability of the translations (including but not limited to local regulations, clinical guidelines, terminology, drug names and drug dosages), and is not responsible for any error and/or omissions arising from translation and adaptation or otherwise.

Open access This is an open access article distributed in accordance with the Creative Commons Attribution Non Commercial (CC BY-NC 4.0) license, which permits others to distribute, remix, adapt, build upon this work non-commercially, and license their derivative works on different terms, provided the original work is properly cited, appropriate credit is given, any changes made indicated, and the use is non-commercial. See: http://creativecommons.org/licenses/by-nc/4.0/.

\section{ORCID iDs}

Carlo Ammendolia http://orcid.org/0000-0003-4417-4961

André Bussières http://orcid.org/0000-0002-2818-6949

James J Young http://orcid.org/0000-0003-1210-3106

Andrea D Furlan http://orcid.org/0000-0001-6138-8510

\section{REFERENCES}

1 Jensen RK, Jensen TS, Koes B, et al. Prevalence of lumbar spinal stenosis in general and clinical populations: a systematic review and meta-analysis. Eur Spine J 2020;29:2143-63.

2 Katz JN, Harris MB, et al. Lumbar spinal stenosis. N Engl J Med 2008;358:818-25.

3 Comer CM, Redmond AC, Bird HA, et al. Assessment and management of neurogenic claudication associated with lumbar spinal stenosis in a UK primary care musculoskeletal service: a survey of current practice among physiotherapists. BMC Musculoskelet Disord 2009;10:121.

4 Kobayashi S, Pathophysiology KS. Pathophysiology, diagnosis and treatment of intermittent claudication in patients with lumbar canal stenosis. World J Orthop 2014;5:134-45.

5 Fritz JM, Delitto A, Welch WC, et al. Lumbar spinal stenosis: a review of current concepts in evaluation, management, and outcome measurements. Arch Phys Med Rehabil 1998;79:700-8.

6 Deyo RA. Treatment of lumbar spinal stenosis: a balancing act. Spine $J$ 2010;10:625-7.

7 Rousing R, Jensen RK, Fruensgaard S, et al. Danish national clinical guidelines for surgical and nonsurgical treatment of patients with lumbar spinal stenosis. Eur Spine J 2019;28:1386-96.

8 Ammendolia C, Stuber K, de Bruin LK, et al. Nonoperative treatment of lumbar spinal stenosis with neurogenic claudication: a systematic review. Spine 2012;37:E609-16.

9 Ammendolia C, Stuber KJ, Rok E, et al. Nonoperative treatment for lumbar spinal stenosis with neurogenic claudication. Cochrane Database Syst Rev 2013;8:CD010712.

10 Moher D, Liberati A, Tetzlaff J, et al. Preferred reporting items for systematic reviews and meta-analyses: the PRISMA statement. Int $J$ Surg 2010;8:336-41.

11 Furlan AD, Pennick V, Bombardier C, et al. 2009 updated method guidelines for systematic reviews in the Cochrane back review group. Spine 2009;34:1929-41.

12 Atkins D, Eccles M, Flottorp S, et al. Systems for grading the quality of evidence and the strength of recommendations I: critical appraisal of existing approaches the grade Working group. BMC Health Serv Res 2004;4:38.

13 Furlan AD, Malmivaara A, Chou R, et al. 2015 updated method guideline for systematic reviews in the Cochrane back and neck group. Spine 2015;40:1660-73.

14 Oğuz H, Levendoğlu F, Karahan AY. Comparison of effects of standard, isokinetic and unloading exercises in the treatment of lumbar spinal stenosis. Turk J Phys Med Rehab 2013;16:1-7.

15 Rodrigues LCL, Natour J, A double-blind NJ. A double-blind, randomized controlled, prospective trial assessing the effectiveness of oral corticoids in the treatment of symptomatic lumbar canal stenosis. J Negat Results Biomed 2014;13:13:13.

16 Amundsen $\mathrm{T}$, Weber $\mathrm{H}$, Nordal $\mathrm{HJ}$, et al. Lumbar spinal stenosis: conservative or surgical management?: a prospective 10-year study. Spine 2000;25:1424-35. discussion 35-6.

17 Zucherman JF, Hsu KY, Hartjen CA, et al. A prospective randomized multi-center study for the treatment of lumbar spinal stenosis 
with the $X$ stop interspinous implant: 1 -year results. Eur Spine $J$ 2004;13:22-31.

18 Whitman JM, Flynn TW, Childs JD, et al. A comparison between two physical therapy treatment programs for patients with lumbar spinal stenosis: a randomized clinical trial. Spine 2006;31:2541-9.

19 Malmivaara A, Slätis P, Heliövaara M, et al. Surgical or nonoperative treatment for lumbar spinal stenosis? A randomized controlled trial. Spine 2007;32:1-8.

20 Pua Y-H, Cai C-C, Lim K-C. Treadmill walking with body weight support is no more effective than cycling when added to an exercise program for lumbar spinal stenosis: a randomised controlled trial. Aust J Physiother 2007;53:83-9.

21 Weinstein JN, Lurie JD, Tosteson TD, et al. Surgical versus nonsurgical treatment for lumbar degenerative spondylolisthesis. $N$ Engl J Med 2007;356:2257-70.

22 Weinstein JN, Tosteson TD, Lurie JD, et al. Surgical versus nonsurgical therapy for lumbar spinal stenosis. N Engl J Med 2008;358:794-810.

23 Koc Z, Ozcakir S, Sivrioglu K, et al. Effectiveness of physical therapy and epidural steroid injections in lumbar spinal stenosis. Spine 2009;34:985-9

24 Goren A, Yildiz N, Topuz O, et al. Efficacy of exercise and ultrasound in patients with lumbar spinal stenosis: a prospective randomized controlled trial. Clin Rehabil 2010;24:623-31.

25 Delitto A, Piva SR, Moore CG, et al. Surgery versus nonsurgical treatment of lumbar spinal stenosis: a randomized trial. Ann Intern Med 2015;162:465-73.

26 Homayouni K, Naseri M, Zaravar F, et al. Comparison of the effect of aquatic physical therapy and conventional physical therapy in patients with lumbar spinal stenosis (a randomized controlled trial). $J$ Musculoskelet Res 2015;18:1550002.

27 Ammendolia C, Côté P, Southerst D, et al. Comprehensive nonsurgical treatment versus Self-directed care to improve walking ability in lumbar spinal stenosis: a randomized trial. Arch Phys Med Rehabil 2018;99:2408-19.

28 Kim K, Shin K-M, Hunt CL, et al. Nonsurgical integrative inpatient treatments for symptomatic lumbar spinal stenosis: a multi-arm randomized controlled pilot trial. J Pain Res 2019;12:1103-13.

29 Marchand A-A, Suitner M, O'Shaughnessy J, et al. Feasibility of conducting an active exercise prehabilitation program in patients awaiting spinal stenosis surgery: a randomized pilot study. Sci Rep 2019;9:12257.

30 Minetama M, Kawakami M, Teraguchi M, et al. Supervised physical therapy vs. home exercise for patients with lumbar spinal stenosis: a randomized controlled trial. Spine J 2019;19:1310-8.

31 Schneider MJ, Ammendolia C, Murphy DR, et al. Comparative clinical effectiveness of nonsurgical treatment methods in patients with lumbar spinal stenosis: a randomized clinical trial. JAMA Netw Open 2019;2:e186828.

32 Cuckler JM, Bernini PA, Wiesel SW, et al. The use of epidural steroids in the treatment of lumbar radicular pain. A prospective, randomized, double-blind study. J Bone Joint Surg Am 1985;67:63-6.

33 Zahaar MS. The value of caudal epidural steroids in the treatment of lumbar neural compression syndromes. J Neurol Orthop Med Surg 1991;12:181-4.

34 Fukusaki M, Kobayashi I, Hara T, et al. Symptoms of spinal stenosis do not improve after epidural steroid injection. Clin J Pain 1998;14:148-51.

35 Brown LL, double-blind A. A double-blind, randomized, prospective study of epidural steroid injection vs. the mild $₫$ procedure in patients with symptomatic lumbar spinal stenosis. Pain Pract 2012;12:333-41.

36 Song SH, Ryu GH, Park JW, et al. The effect and safety of steroid injection in lumbar spinal stenosis: with or without local anesthetics. Ann Rehabil Med 2016;40:14-20.

37 Friedly JL, Comstock BA, Turner JA, et al. A randomized trial of epidural glucocorticoid injections for spinal stenosis. N Engl J Med 2014;371:11-21.

38 Milburn J, Freeman J, Steven A, et al. Interlaminar epidural steroid injection for degenerative lumbar spinal canal stenosis: does the intervertebral level of performance matter? Ochsner J 2014;14:62-6.

39 Karm M-H, Choi S-S, Kim D-H, et al. Percutaneous epidural adhesiolysis using inflatable balloon catheter and balloonless catheter in central lumbar spinal stenosis with neurogenic claudication: a randomized controlled trial. Pain Physician 2018;21:593-606.

40 Hammerich A, Whitman J, Mintken P, et al. Effectiveness of physical therapy combined with epidural steroid injection for individuals with lumbar spinal stenosis: a randomized parallel-group trial. Arch Phys Med Rehabil 2019;100:797-810.
41 Sencan S, Edipoglu IS, Celenlioglu AE, et al. Comparison of treatment outcomes in lumbar central stenosis patients treated with epidural steroid injections: interlaminar versus bilateral transforaminal approach. Korean J Pain 2020;33:226-33.

42 Wei P, Xu Y, Yao Q, et al. Randomized trial of 3-drug combination for lumbar nerve root epidural injections with a TNF- $\alpha$ inhibitor in treatment of lumbar stenosis. Br J Neurosurg 2020;34:168-71.

43 Matsudaira K, Seichi A, Kunogi J, et al. The efficacy of prostaglandin E1 derivative in patients with lumbar spinal stenosis. Spine 2009;34:115-20.

44 Waikakul W, Waikakul S. Methylcobalamin as an adjuvant medication in conservative treatment of lumbar spinal stenosis. J Med Assoc Thai 2000;83:825-31.

45 Yaksi A, Ozgönenel L, Ozgönenel B. The efficiency of gabapentin therapy in patients with lumbar spinal stenosis. Spine 2007;32:939-42.

46 Markman JD, Frazer ME, Rast SA, et al. Double-Blind, randomized, controlled, crossover trial of pregabalin for neurogenic claudication. Neurology 2015;84:265-72.

47 Markman JD, Gewandter JS, Frazer ME, et al. A randomized, double-blind, placebo-controlled crossover trial of oxymorphone hydrochloride and propoxyphene/acetaminophen combination for the treatment of neurogenic claudication associated with lumbar spinal stenosis. Spine 2015;40:684-91.

48 Park SJ, Yoon KB, Yoon DM, et al. Botulinum toxin treatment for nocturnal calf cramps in patients with lumbar spinal stenosis: a randomized clinical trial. Arch Phys Med Rehabil 2017;98:957-63.

49 Porter RW, Hibbert C. Calcitonin treatment for neurogenic claudication. Spine 1983;8:585-92.

50 Porter RW, Miller CG. Neurogenic claudication and root claudication treated with calcitonin. A double-blind trial. Spine 1988;13:1061-4.

51 Eskola A, Pohjolainen T, Alaranta $\mathrm{H}$, et al. Calcitonin treatment in lumbar spinal stenosis: a randomized, placebo-controlled, doubleblind, cross-over study with one-year follow-up. Calcif Tissue Int 1992;50:400-3.

52 Podichetty VK, Segal AM, Lieber M, et al. Effectiveness of salmon calcitonin nasal spray in the treatment of lumbar canal stenosis: a double-blind, randomized, placebo-controlled, parallel group trial. Spine 2004;29:2343-9.

53 Sahin F, Yilmaz F, Kotevoglu N, et al. The efficacy of physical therapy and physical therapy plus calcitonin in the treatment of lumbar spinal stenosis. Yonsei Med J 2009;50:683-8.

54 Tafazal SI, Ng L, Sell P. Randomised placebo-controlled trial on the effectiveness of nasal salmon calcitonin in the treatment of lumbar spinal stenosis. Eur Spine J 2007;16:207-12.

$55 \mathrm{Kim} \mathrm{KH}$, Kim YR, Baik SK, et al. Acupuncture for patients with lumbar spinal stenosis: a randomised pilot trial. Acupunct Med 2016;34:267-74.

56 Qin Z, Ding Y, Xu C, et al. Acupuncture vs noninsertive sham acupuncture in aging patients with degenerative lumbar spinal stenosis: a randomized controlled trial. $A m \mathrm{~J}$ Med 2020;133:e20:500-7.

57 Passmore SR, Johnson MG, Aloraini SM, et al. Impact of spinal manipulation on lower extremity motor control in lumbar spinal stenosis patients: a small-scale assessor-blind randomized clinical trial. J Manipulative Physiol Ther 2019;42:23-33.

58 Lurie JD, Tosteson TD, Tosteson A, et al. Long-Term outcomes of lumbar spinal stenosis: eight-year results of the spine patient outcomes research trial (sport). Spine 2015;40:63-76.

59 Hsu KY, Zucherman JF, Hartjen CA, et al. Quality of life of lumbar stenosis-treated patients in whom the $X$ stop interspinous device was implanted. J Neurosurg Spine 2006;5:500-7.

60 Zucherman JF, Hsu KY, Hartjen CA, et al. A multicenter, prospective, randomized trial evaluating the $X$ stop interspinous process decompression system for the treatment of neurogenic intermittent claudication: two-year follow-up results. Spine 2005;30:1351-8.

61 Abdu WA, Sacks OA, Tosteson ANA, et al. Long-term results of surgery compared with nonoperative treatment for lumbar degenerative spondylolisthesis in the spine patient outcomes research trial (sport). Spine 2018;43:1619-30.

62 Friedly JL, Comstock BA, Turner JA, et al. Long-Term effects of repeated injections of local anesthetic with or without corticosteroid for lumbar spinal stenosis: a randomized trial. Arch Phys Med Rehabil 2017;98:1499-507.

63 Cleland JA, Whitman JM, Houser JL, et al. Psychometric properties of selected tests in patients with lumbar spinal stenosis. Spine $J$ 2012;12:921-31.

64 Makris UE, Edwards TC, Lavallee DC, et al. Patient priority weighting of the Roland Morris disability questionnaire does not change results of the lumbar epidural steroid injections for spinal stenosis trial. Spine 2017;42:42-8. 
65 Bussières A, Cancelliere C, Ammendolia C, et al. Non-Surgical interventions for lumbar spinal stenosis leading to neurogenic claudication: a clinical practice guideline. J Pain 2021;22:1015-39.

66 Jacobi S, Beynon A, Dombrowski SU, et al. Effectiveness of conservative nonpharmacologic therapies for pain, disability, physical capacity, and physical activity behavior in patients with degenerative lumbar spinal stenosis: a systematic review and meta-analysis. Arch Phys Med Rehabil 2021;102:2247-60.

67 Jensen RK, Harhangi BS, Huygen F, et al. Lumbar spinal stenosis. BMJ 2021;61:n1581.

68 Kreiner DS, Shaffer WO, Baisden JL, et al. An evidence-based clinical guideline for the diagnosis and treatment of degenerative lumbar spinal stenosis (update). Spine J 2013;13:734-43.

69 Macedo LG, Hum A, Kuleba L, et al. Physical therapy interventions for degenerative lumbar spinal stenosis: a systematic review. Phys Ther 2013;93:1646-60.

70 Ammendolia C, Schneider M, Williams K, et al. The physical and psychological impact of neurogenic claudication: the patients' perspectives. J Can Chiropr Assoc 2017;61:18-31.

71 Friedly J, Chan L, Deyo R. Increases in lumbosacral injections in the Medicare population: 1994 to 2001. Spine 2007;32:1754-60.

72 Friedly J, Nishio I, Bishop MJ, et al. The relationship between repeated epidural steroid injections and subsequent opioid use and lumbar surgery. Arch Phys Med Rehabil 2008;89:1011-5.

73 Bresnahan BW, Rundell SD, Dagadakis MC, et al. A systematic review to assess comparative effectiveness studies in epidural steroid injections for lumbar spinal stenosis and to estimate reimbursement amounts. Pm R 2013;5:705-14.

74 Chou R, Hashimoto R, Friedly J, et al. Epidural corticosteroid injections for radiculopathy and spinal stenosis: a systematic review and meta-analysis. Ann Intern Med 2015;163:373-81.

75 Liu K, Liu P, Liu R, et al. Steroid for epidural injection in spinal stenosis: a systematic review and meta-analysis. Drug Des Devel Ther 2015;9:707-16.

76 Deyo RA, Mirza SK, Martin BI, et al. Trends, major medical complications, and charges associated with surgery for lumbar spina stenosis in older adults. JAMA 2010;303:1259-65.

77 Machado GC, Maher CG, Ferreira PH, et al. Trends, complications, and costs for hospital admission and surgery for lumbar spinal stenosis. Spine 2017;42:1737-43.

78 Machado GC, Ferreira PH, Yoo RI, et al. Surgical options for lumbar spinal stenosis. Cochrane Database Syst Rev 2016;11:CD012421.

79 Zaina F, Tomkins-Lane C, Carragee E, et al. Surgical versus nonsurgical treatment for lumbar spinal stenosis. Spine 2016;41:E857-68.

80 Anderson DB, Mobbs RJ, Eyles J, et al. Barriers to participation in a placebo-surgical trial for lumbar spinal stenosis. Heliyon 2019;5:e01683.

81 Anderson DB, Ferreira ML, Harris IA, et al. Success, surgery for spinal stenosis: protocol of a randomised, placebo-controlled trial. BMJ Open 2019;9:e024944.

82 Enke O, New HA, New CH, et al. Anticonvulsants in the treatment of low back pain and lumbar radicular pain: a systematic review and meta-analysis. CMAJ 2018;190:E786-93.

83 Qaseem A, Wilt TJ, McLean RM, et al. Noninvasive treatments for acute, subacute, and chronic low back pain: a clinical practice guideline from the American College of Physicians. Ann Intern Med 2017;166:514-30.

84 Shanthanna H, Gilron I, Rajarathinam M, et al. Benefits and safety of gabapentinoids in chronic low back pain: a systematic review and meta-analysis of randomized controlled trials. PLoS Med 2017; $14:$ e1002369

$85 \mathrm{Kim} \mathrm{KH}$, Kim T-H, Lee BR, et al. Acupuncture for lumbar spinal stenosis: a systematic review and meta-analysis. Complement Ther Med 2013;21:535-56.

86 Bussières AE, Stewart G, Al-Zoubi F, et al. Spinal manipulative therapy and other conservative treatments for low back pain: a guideline from the Canadian chiropractic guideline initiative. $J$ Manipulative Physiol Ther 2018;41:265-93.

87 Schulz KF, Altman DG, Moher D, et al. Consort 2010 statement: updated guidelines for reporting parallel group randomised trials. J Clin Epidemiol 2010;63:834-40.

88 Chou R, Baisden J, Carragee EJ, et al. Surgery for low back pain: a review of the evidence for an American pain Society clinical practice guideline. Spine 2009;34:1094-109.

89 Kovacs FM, Urrútia G, Alarcón JD. Surgery versus conservative treatment for symptomatic lumbar spinal stenosis: a systematic review of randomized controlled trials. Spine 2011;36:E1335-51.

90 Suri P, Rainville J, Kalichman L, et al. Does this older adult with lower extremity pain have the clinical syndrome of lumbar spinal stenosis? JAMA 2010;304:2628-36.

91 Anderson SF, Kelley K, Maxwell SE. Sample-size planning for more accurate statistical power: a method adjusting sample effect sizes for publication bias and uncertainty. Psychol Sci 2017;28:1547-62.

92 Carlesso CPS, Smith C, Ammendolia C. Responsiveness of outcome measures in non-surgical patients with lumbar spinal stenosis a secondary analysis from a randomized controlled trial. Spine 2020.

93 Wertli MM, Buletti FC, Held U, et al. A comparison between different outcome measures based on "meaningful important differences" in patients with lumbar spinal stenosis. Eur Spine $J$ 2017;26:450-61.

94 Ostelo RWJG, de Vet HCW. Clinically important outcomes in low back pain. Best Pract Res Clin Rheumatol 2005;19:593-607.

95 Boden SD, Davis DO, Dina TS, et al. Abnormal magnetic-resonance scans of the lumbar spine in asymptomatic subjects. A prospective investigation. J Bone Joint Surg Am 1990;72:403-8.

96 Haig AJ, Tong HC, Yamakawa KS, et al. Spinal stenosis, back pain or no symptoms at all? A masked study comparing radiologic and electrodiagnostic diagnoses to the clinical impression. Arch Phys Med Rehabil 2006;87:897-903.

97 Genevay S, Courvoisier DS, Konstantinou K, et al. Clinical classification criteria for neurogenic claudication caused by lumbar spinal stenosis. The N-CLASS criteria. Spine J 2018;18:941-7.

98 Weinstein JN, Lurie JD, Tosteson TD, et al. Surgical compared with nonoperative treatment for lumbar degenerative spondylolisthesis. four-year results in the spine patient outcomes research trial (sport) randomized and observational cohorts. J Bone Joint Surg Am 2009:91:1295-304

99 Weinstein JN, Tosteson TD, Lurie JD, et al. Surgical versus nonoperative treatment for lumbar spinal stenosis four-year results of the spine patient outcomes research trial. Spine 2010;35:1329-38. 